\title{
The role of fabric diffusers in delivering indoor air quality and enhancing energy performance
}

\author{
A. J. Geens, D. G. Snelson \& H. Al-Madfai \\ Faculty of Advanced Technology, University of Glamorgan, UK
}

\begin{abstract}
According to UK Building Regulations, Approved Document F, published in 2006, ventilation system effectiveness can range from zero (complete short circuiting) to infinity (perfect displacement/piston). The rate of supply of fresh air required to achieve a particular air quality is directly related to ventilation effectiveness; the greater the effectiveness, the less fresh air required. At a time of heightened awareness of the need for carbon reduction measures, this must be of interest to designers of ventilation systems. The volume of fresh air required impacts on energy use in two ways: firstly in terms of the electrical energy to move the volume of air through the building (fan power), and secondly in terms of energy to condition the air (heating or cooling). In the course of performance testing ventilation systems designed to control environmental tobacco smoke, the authors have examined the performance of a number of different techniques. This paper reports on some of the better techniques observed, which may prove useful in other applications, both in terms of improving the control of indoor air quality and also in reducing carbon impact in achieving that air quality.
\end{abstract}

Keywords: fabric diffusers, ventilation, indoor air quality (IAQ), energy performance.

\section{Introduction}

The impact of indoor air quality on energy performance is acknowledged in BS EN 15251 [1], Indoor environmental parameters for design and assessment of energy performance of buildings addressing indoor air quality, thermal environment, lighting and acoustics. This standard has been developed to harmonise an energy performance of buildings calculation methodology to meet the requirements of the Energy Performance of Buildings Directive. UK 
Building Regulations, Approved Document F [2] asserts that ventilation system effectiveness can range from zero, (complete short circuiting), to infinity, (perfect displacement/piston). The rate of supply of fresh air required to achieve a particular air quality is directly related to ventilation effectiveness; the greater the effectiveness, the less fresh air required. A ventilation rate calculation methodology that takes account of ventilation effectiveness is described in PD CR 1752 [3]. The required ventilation rate can be calculated from:

$$
Q_{C}=10 \frac{G}{C_{i}-C_{o}} \frac{1}{\varepsilon_{v}}
$$

where: $Q_{c}=$ Fresh air ventilation rate $(1 / \mathrm{s}), G=$ Pollution load on building (olfs)

$C_{i}=$ The desired air quality (decipol), $C_{o}=$ The outdoor AQ (decipols)

$\varepsilon_{v}=$ The ventilation effectiveness (dimensionless)

Ventilation effectiveness

$$
\varepsilon_{\mathrm{v}}=\frac{\mathrm{C}_{\mathrm{e}}-\mathrm{C}_{\mathrm{s}}}{\mathrm{C}_{\mathrm{i}}-\mathrm{C}_{\mathrm{s}}}
$$

where: $\quad C_{e}=$ Pollution concentration in exhaust air

$C_{s}=$ Pollution concentration in supply air

$C_{i}=$ Pollution concentration in breathing zone

If the supply air is assumed to be unpolluted, the formula becomes:

$$
\varepsilon_{\mathrm{v}}=\frac{\mathrm{C}_{\mathrm{e}}}{\mathrm{C}_{\mathrm{i}}}
$$

\begin{tabular}{|c|c|c|c|c|c|}
\hline \multicolumn{2}{|c|}{ Mixing Ventilation } & \multicolumn{2}{|c|}{ Mixing Ventilation } & \multicolumn{2}{|c|}{ Displacement Ventilation } \\
\hline $\begin{array}{c}\text { Temperature } \\
\text { difference } \\
\text { between supply } \\
\text { air and air in } \\
\text { breathing zone } \\
\mathrm{t}_{\mathrm{s}}-\mathrm{t}_{\mathrm{i}} \\
{ }^{\circ} \mathrm{C}\end{array}$ & $\begin{array}{l}\text { Ventilation } \\
\text { effectiveness }\end{array}$ & $\begin{array}{c}\text { Temperature } \\
\text { difference } \\
\text { between supply } \\
\text { air and air in } \\
\text { breathing zone } \\
\mathrm{t}_{\mathrm{s}}-\mathrm{t}_{\mathrm{i}} \\
{ }^{\circ} \mathrm{C}\end{array}$ & $\begin{array}{l}\text { Ventilation } \\
\text { effectiveness }\end{array}$ & $\begin{array}{c}\text { Temperature } \\
\text { difference } \\
\text { between supply } \\
\text { air and air in } \\
\text { breathing zone } \\
t_{s}-t_{i} \\
{ }^{\circ} \mathrm{C}\end{array}$ & $\begin{array}{l}\text { Ventilation } \\
\text { effectiveness }\end{array}$ \\
\hline $\begin{array}{c}<0 \\
0-2 \\
2-5 \\
>5\end{array}$ & $\begin{array}{c}0.9-1.0 \\
0.9 \\
0.8 \\
0.4-0.7\end{array}$ & $\begin{array}{c}<-5 \\
-5-0 \\
>0\end{array}$ & $\begin{array}{c}0.9 \\
0.9-1.0 \\
1.0\end{array}$ & $\begin{array}{c}<0 \\
0-2 \\
>2\end{array}$ & $\begin{array}{l}1.2-1.4 \\
0.7-0.9 \\
0.2-0.7\end{array}$ \\
\hline
\end{tabular}

Table 1: Examples of ventilation effectiveness in the breathing zone of spaces ventilated in different ways (source PD CR 1752 [3]). 
As can be observed in eqn (1), if the ventilation effectiveness is greater than one, the required ventilation rate is reduced. From eqn (2) it can be observed that the smaller the difference in concentration in the air supply and the breathing zone, the greater the ventilation effectiveness. Table 1 shows that in the right circumstances, displacement ventilation can achieve effectiveness values greater than 1. Although published in 1999, this table first appeared in Guidelines for Ventilation Requirements for Buildings. Report no.11 [4], published in 1992. At that time displacement ventilation was relatively new and the effectiveness figures were cautious, and in the light of subsequent work it is reasonable to expect much higher values (Wyatt [5]) with their associated energy benefits. In 2000, following tests carried out at the BSRIA laboratories in Crowthorne, Geens [6] proposed that fabric diffusers installed at low level could serve as displacement ventilation supply diffusers and facilitate high air flow rates and hence high cooling capacity without draught or noise risk. It was demonstrated that this technique could increase cooling capacity to $50 \mathrm{~W} / \mathrm{m}^{2}$, Abbas [7], Geens [8] also concluded that this displacement technique would be useful where high flow rates were required to deal with specific contaminant concerns as a result of the high ventilation effectiveness achievable, i.e. flow rate for air quality rather than cooling. In this case the increased ventilation effectiveness available with displacement ventilation would help to mitigate the need for such high flow rates with an associated energy benefit. The work at the BSRIA laboratories was repeated by Butler [9] at the BRE laboratories re-affirming the findings of Geens.

\subsection{Ventilation in licensed premises}

Buildings should be adequately ventilated as defined by the Buildings Regulations 2000, Part F [2]. In 2003 Geens began a series of ventilation effectiveness surveys of new or upgraded ventilation systems installed in pubs that had been designed to provide improved air quality, specifically in the bar serving area, but for the whole building as a consequence. The ventilation system would reduce the exposure concentrations of environmental tobacco smoke (ETS) of bars staff and customers. This work introduced the opportunity for discussions with the system designers and consequently to the inclusion of fabric diffusers for the ventilation systems in two pubs, moving the work from the laboratory to the field. This work was utilising the high volume flow rate potential of the diffusers for air quality benefits rather than the enhanced cooling capability, although the high ventilation effectiveness achievable mitigated the need for even higher volume flow rates and associated energy costs. The premises that took part in the studies were: The Bakers Arms in Waddesdon near Aylesbury, UK and the Hairy Canary in Brussels, Belgium.

\section{Experimental method}

There were no restrictions on smoking in the premises at the time of the research. Smoking was allowed at the bar counter. The airborne contaminants that were 
measured can be harmful in high concentrations. Examples of the levels of acceptable worker exposure are set out below, and as can be seen, they are not consistent between countries.

OSHA [10]: Enforceable maximum exposures for industrial environments developed by OSHA (US Department of Labor, Occupational Safety and Health Administration) through a formal rule-making process. Once an exposure limit has been set, levels can be changed only through reopening the rule-making process. These permissible exposure limits (PELs) are not selected to protect the most sensitive individuals.

MAK [11]: Recommended maximum exposures for industrial environments developed by the Deutsche Forschungs-Gemeinschaft, a German institution similar to the U.S. National Institute for Occupational Safety and Health $(\mathrm{NIOSH})$. Levels are set on a regular basis, with annual reviews and periodic republication of criteria levels. These levels are enforceable in Germany and are not selected to protect the most sensitive individuals.

HSE [12]: Recommended maximum exposures for industrial environments developed by Health and Safety Commission, which is responsible for health and safety regulation in the United Kingdom. Levels and limits, which are regularly reviewed and updated, are enforceable in the United Kingdom and are not selected to protect the most sensitive individuals.

The European Standard EN 13779 [13] further sets out a basic classification for indoor air quality (IDA) based upon the average level of carbon dioxide in the air over an 8 hour period.

Table 2: $\quad$ Example standards.

\begin{tabular}{||c|c|c|c|c||}
\hline \hline \multicolumn{2}{||c|}{} & OSHA & MAK & HSE \\
\cline { 3 - 5 } & & USA & Germany & UK \\
\hline Carbon Dioxide & $\mathrm{CO}_{2}$ & $5000 \mathrm{ppm}$ & $5000 \mathrm{ppm}$ & $5000 \mathrm{ppm}$ \\
\hline Carbon Monoxide & $\mathrm{CO}$ & $50 \mathrm{ppm}$ & $30 \mathrm{ppm}$ & $30 \mathrm{ppm}$ \\
\hline Respirable Particles $<2.5 \mu \mathrm{m}$ & $\mathrm{PM} 2.5$ & $5 \mathrm{mg} / \mathrm{m}^{3}$ & $1.5^{*} \mathrm{mg} / \mathrm{m}^{3}$ & $4 \mathrm{mg} / \mathrm{m}^{3}$ \\
\hline
\end{tabular}

*Note: this standard applies to $<4 \mu \mathrm{m}$. The level would be lower for PM 2.5.

Table 3: $\quad$ EN 13779 Standard.

\begin{tabular}{||c|c|c||}
\hline \hline Category & Description & CO $_{2}$ level in room (above ambient external) \\
\hline IDA 1 & High indoor air quality & $<400 \mathrm{ppm}$ \\
\hline IDA 2 & Medium indoor air quality & $400-600 \mathrm{ppm}$ \\
\hline IDA 3 & Moderate indoor air quality & $600-1000 \mathrm{ppm}$ \\
\hline IDA 4 & Low indoor air quality & $>1000 \mathrm{ppm}$ \\
\hline
\end{tabular}


The studies were all arranged to coincide with busy times of the week. Continuous real-time monitoring was carried out to ensure that peak exposure conditions were captured and to measure baseline levels of markers during the overnight period of no occupancy. The results from the instruments will be used to demonstrate the ventilation effectiveness. Additionally, Draeger smoke tubes were used during the set-up procedure to visualise and confirm the expected air flow patterns in the room. The sampling devices were located in the bar serving area at a height approximating to the breathing zone. A seating plan, layout of the pubs and where the ventilation grilles were positioned was recorded. Measurements were taken to ascertain the internal volume of the premises. During the monitoring period the number of cigarettes smoked per hour was recorded. To facilitate comparison with other buildings this data was converted to cigarettes per hour per $\mathrm{m}^{3}$ of building volume and is presented graphically with the monitoring results in this way.

Three ETS markers were used in the studies, carbon dioxide $\left(\mathrm{CO}_{2}\right)$, carbon monoxide (CO), Respirable Suspended Particles (PM2.5), and temperature. $\mathrm{CO}_{2}$ was recorded as this is the contaminant most usually used to control the operation of variable speed ventilation systems and is a useful indicator that the ventilation system is operating correctly at the outset. These markers are simple and inexpensive to monitor which was an important consideration when undertaking a series of investigations over a period of time. Although other markers have been used in other studies, the selection of markers is actually unimportant when assessing ventilation performance, as according to Dalton's Law of Partial Pressure (Dean, [14]):

\section{"A gas mixture behaves in exactly the same fashion as a pure gas"}

The sampling devices used were the Dustrak Aerosol Monitor Model 8520 by TSI Inc, using the $2.5 \mu \mathrm{m}$ inlet conditioner and a flow rate of $1.7 \mathrm{l} / \mathrm{min}$, and the Q-Trak Plus IAQ Monitor Model 8554 by TSI Inc (Cains [15]). During the busy periods an hourly cigarette count was taken. Levels of Respirable Suspended Particles (PM 2.5), carbon monoxide, carbon dioxide and temperature were recorded. The rationale for this is as follows:

\subsection{Respirable suspended particles (PM 2.5)}

Respirable suspended particles (PM 2.5) are a constituent of environmental tobacco smoke and serve as a marker, although they are produced from other sources in buildings as well. The workplace exposure limit ( 8 hour time weighted average) for respirable particles is typically $4 \mathrm{mg} / \mathrm{m}^{3}$ (HSE [12]), however there is no ETS specific figure provided. A number of other particle phase or vapour phase markers may be monitored when assessing ventilation performance in dealing with ETS, but to do so in these studies would have extended the timescale and costs unacceptably. The aim of the studies was to demonstrate the effectiveness of a fabric diffuser in dealing with ETS and by monitoring a solid, (PM 2.5), and a gaseous, (CO) constituent it is possible to indicate the likely effectiveness of the system for a wider range of constituents. 
Reference to workplace exposure limits is appropriate in these studies as the monitoring is taking place behind the bar.

\subsection{Carbon monoxide}

Carbon monoxide is a constituent of environmental tobacco smoke (ETS) but is sometimes considered unsuitable as an ETS marker, as it has other sources for example combustion of petrol and diesel from cars and lorries. The advantages of ease of real-time recording and the existence of recognised occupational exposure standards for carbon monoxide outweighed this concern. Additionally any carbon monoxide from other sources will make the test conditions more onerous, not less. The workplace exposure limit ( 8 hour time weighted average) for carbon monoxide is 30 ppm (HSE [12]).

\subsection{Carbon dioxide}

Carbon dioxide is produced wherever people are present in buildings, as a product of respiration as well as being an ETS constituent. It is therefore usual to use carbon dioxide as an indication of the effectiveness of the ventilation system. For the purposes of this study it is important to establish that the ventilation is performing effectively at the outset. Levels of $\mathrm{CO}_{2}$ are not likely to reach levels of health concern for a building in normal use. A figure of $5000 \mathrm{ppm}$ is identified in EH40/2005 [12] as the recommended 8 hour average exposure limit. For comfort level/odour dilution, a $\mathrm{CO}_{2}$ limit of $1000 \mathrm{ppm}$ is recommended in BSRIA Technical Note 2/2002 [16]. It is worth noting that carbon dioxide is present in fresh air at around 400ppm and so unlike the other indicators, carbon dioxide will not tend towards zero.

\subsection{Temperature}

There are requirements under Health Safety legislation relating to the provision of a satisfactory thermal environment. Monitoring of these parameters satisfies two objectives, firstly to establish that in improving the air quality the ventilation is not having a negative impact on thermal comfort, and secondly to establish whether it is actually enhancing thermal comfort. Ideally temperatures should be maintained between $19{ }^{\circ} \mathrm{C}$ and $24{ }^{\circ} \mathrm{C}$, and relative humidity between 40 and $70 \%$ (CIBSE [17]).

\subsection{Cigarette count}

The number of cigarettes consumed was measured on an hourly basis through a count of the cigarette butts collected in ashtrays; to produce a measure of cigarettes/hour. To gain a fair comparison with other studies in venues of different sizes the cigarette count has been divided by the volume of the premises, to provide a measure of cigarettes $/ \mathrm{m}^{3} /$ hour. From our research in a number of countries and situations, all in venues where smoking is permitted and on the busiest evenings of the week, we have categorised the levels of smoke released in the space as in Table 4. 
Table 4: $\quad$ Smoking rates.

\begin{tabular}{||c|c||}
\hline \hline & 8 -hr average cig $/ \mathrm{m}^{3} / \mathrm{hr}$ \\
\hline Very Heavy & $0.31+$ \\
\hline Heavy & $0.16-0.30$ \\
\hline Moderate & $0.06-0.15$ \\
\hline Light & $<0.05$ \\
\hline
\end{tabular}

For reference the highest hourly level of smoking $/ \mathrm{m}^{3}$ recorded in our field research was 0.69 cigarettes $/ \mathrm{m}^{3} /$ hour. This was exceptionally high and was only sustained for one hour.

\subsection{Ventilation system turns off}

When customers were smoking heavily the ventilation system was turned off for approximately 10 minutes. This was to simulate conditions prior to the installation of the new system and to illustrate the effectiveness of the ventilation system on air quality inside the premises.

\section{Results}

\subsection{Bakers Arms, Waddesdon}

\subsubsection{Carbon monoxide}

The results of the monitoring for $\mathrm{CO}$ can also be seen in Figures 1(a) and (b). Figure 1(a) shows that, with the ventilation running, the $\mathrm{CO}$ levels rarely register on the instruments. Figure 1(b) shows that when the ventilation and filtration units are out of service, the $\mathrm{CO}$ levels rise rapidly, on this occasion to approximately $7 \mathrm{ppm}$ behind the bar and approximately $4 \mathrm{ppm}$ in the customer area, but when the ventilation is re-instated, the readings return very quickly to their earlier levels.

\subsubsection{Carbon dioxide}

The results of the monitoring for $\mathrm{CO}_{2}$ can be seen in Figures 1(a) and (b). Figure 1(a) shows that, with the ventilation running, the $\mathrm{CO}_{2}$ levels are normally limited to less than $710 \mathrm{ppm}$ behind the bar and less than $760 \mathrm{ppm}$ in the customer area. Figure 1(b) shows that when the ventilation and filtration units are out of service, the $\mathrm{CO}_{2}$ levels rises, on this occasion to approximately $2800 \mathrm{ppm}$ behind the bar and approximately $3100 \mathrm{ppm}$ in the customer area, but when the ventilation is re-instated, the readings return very quickly to their earlier levels, demonstrating the effectiveness of the ventilation system. Figure 3(a) indicates that $\mathrm{CO}_{2}$ levels 


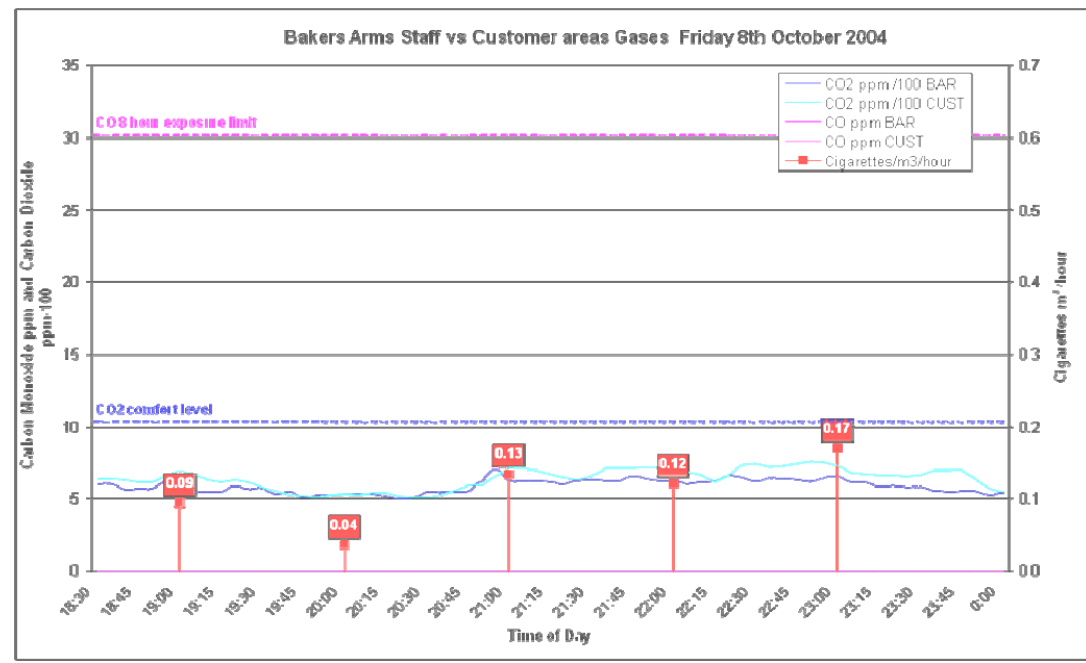

(a)

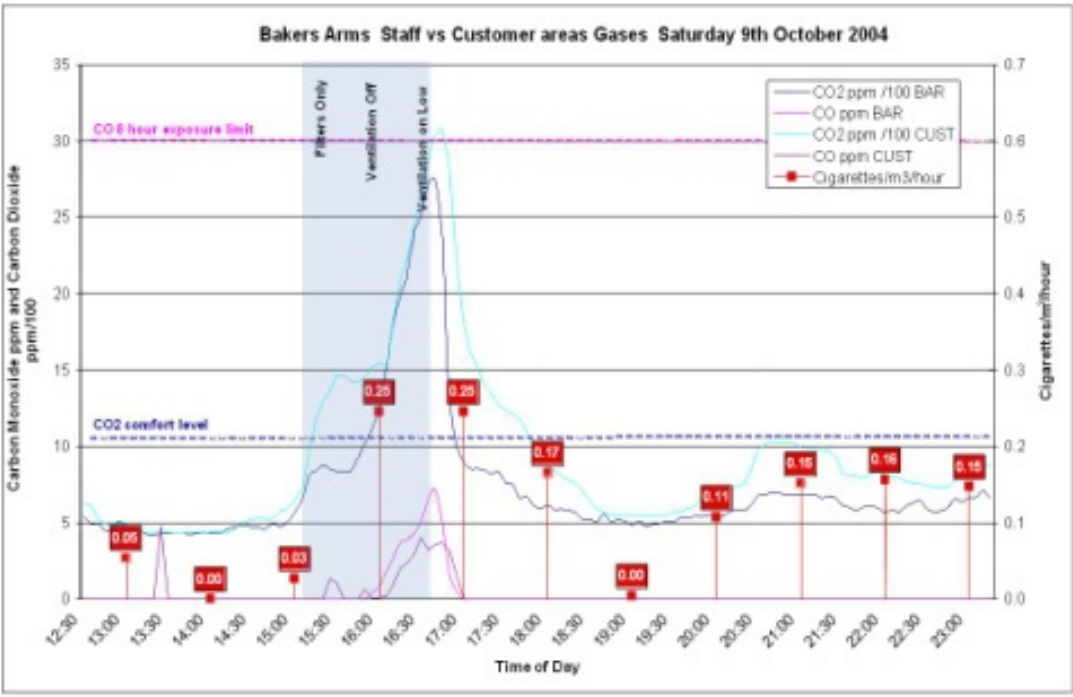

(b)

Figure 1: Bakers Arms gas monitoring.

overnight fall to ambient levels in fresh air as would be expected in a rural location. The workplace exposure limit noted above is an average of $5000 \mathrm{ppm}$ over an eight-hour period as a cause for concern and $1000 \mathrm{ppm}$ being the accepted level for comfort and odour control.

\subsubsection{Particulate (PM 2.5)}

The results of the monitoring for Respirable Suspended Particles (PM 2.5) can be seen in Figures 2(a) and (b). Figure 2(a) shows that with the ventilation and 


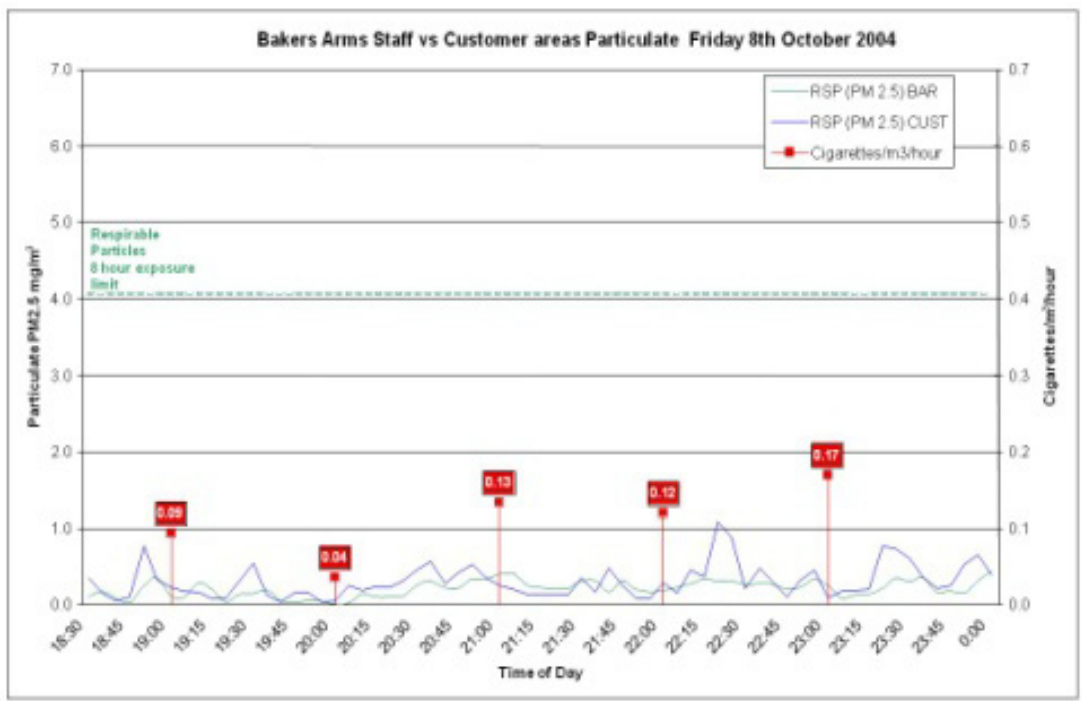

(a)

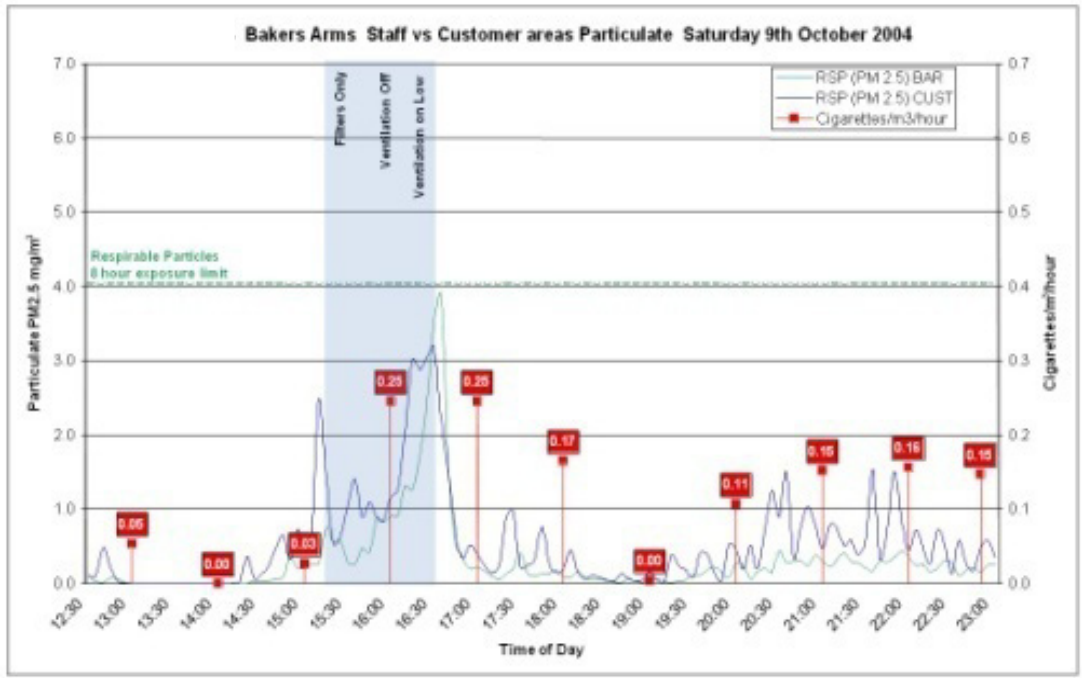

(b)

Figure 2: $\quad$ Bakers Arms particulate monitoring.

filtration units running particulate is generally limited to below $0.5 \mathrm{mg} / \mathrm{m}^{3}$ behind the bar counter and less than $1.0 \mathrm{mg} / \mathrm{m}^{3}$ in the customer area. Figure 2(b) shows that when the ventilation and filtration units are out of service, the particulate level rapidly rises, on this occasion to approximately $3.9 \mathrm{mg} / \mathrm{m}^{3}$ behind the bar and approximately $3.2 \mathrm{mg} / \mathrm{m}^{3}$ in the customer area. When the systems are reinstated, the readings return very quickly to their earlier levels. 


\subsubsection{Cigarette count}

The level of smoking was relatively high for the venue and peaked during the football international at a rate of 55 cigarettes an hour $\left(0.25 \mathrm{cigs} / \mathrm{m}^{3} /\right.$ hour $)$. This is likely to be at, or close to, the maximum smoking rate for the outlet. For the remainder of the monitored period smoking was in the range of 0.1 to 0.2 cigs $/ \mathrm{m}^{3} /$ hour, which is the normal level of smoking on busy nights in the outlets surveyed to date.

\subsection{The Hairy Canary Irish pub, Brussels}

\subsubsection{Carbon monoxide}

The results of the monitoring for $\mathrm{CO}$ can be seen in Figures 3(a) and (b). Figure 3(a) shows that, with the ventilation running, the $\mathrm{CO}$ levels are kept close to 0 ppm. The figure shows that when the ventilation system was switched off, the CO levels quickly rose to approximately $3.5 \mathrm{ppm}$. Almost immediately after the ventilation system was switched back on, the $\mathrm{CO}$ readings dropped to their previous levels close to 0 , which demonstrates the effectiveness of the ventilation system.

\subsection{Carbon dioxide}

The results of the monitoring for $\mathrm{CO}_{2}$ can be seen in Figures 3(a) and 4(b). Figure 3(a) shows that, with the ventilation running, the $\mathrm{CO}_{2}$ levels were limited to below $700 \mathrm{ppm}$. When the ventilation system was switched off, the $\mathrm{CO}_{2}$ levels rose, on this occasion to approximately $1500 \mathrm{ppm}$, but when the ventilation was switched back on, the readings return very quickly to their earlier levels, demonstrating the effectiveness of the ventilation system. Readings taken outside the pub on the day of the ventilation effectiveness study indicate that outdoor level of $\mathrm{CO}_{2}$ was approximately $430 \mathrm{ppm}$. Therefore the relevant European air quality standards are as in Table 5.

The carbon dioxide readings indicated that for the entire measured period there was 'High Air Quality' (IDA1) except for the brief period with the ventilation switched off and immediately afterwards.

Table 5: $\quad$ Site related air quality standards.

\begin{tabular}{||c|c|c||}
\hline \hline Category & Description & $\mathbf{C O}_{\mathbf{2}}$ level in room \\
\hline IDA 1 & High indoor air quality & $<830 \mathrm{ppm}$ \\
\hline IDA 2 & Medium indoor air quality & $830-1030 \mathrm{ppm}$ \\
\hline IDA 3 & Moderate indoor air quality & $1030-1430 \mathrm{ppm}$ \\
\hline IDA 4 & Low indoor air quality & $>1430 \mathrm{ppm}$ \\
\hline
\end{tabular}




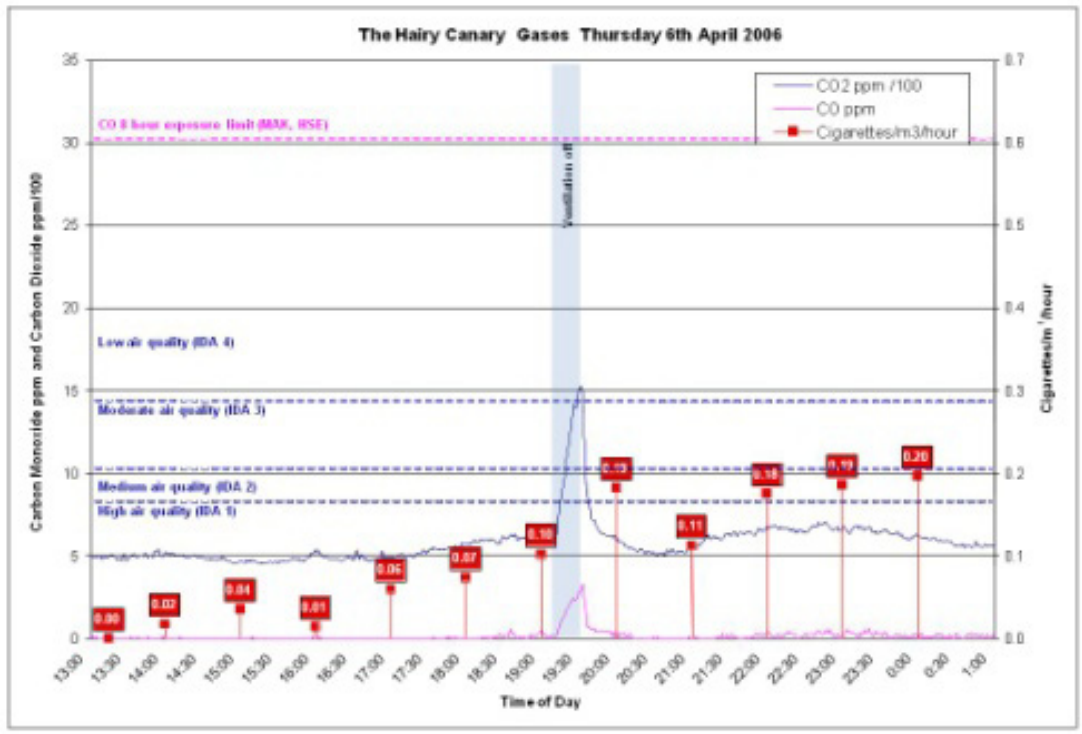

(a)

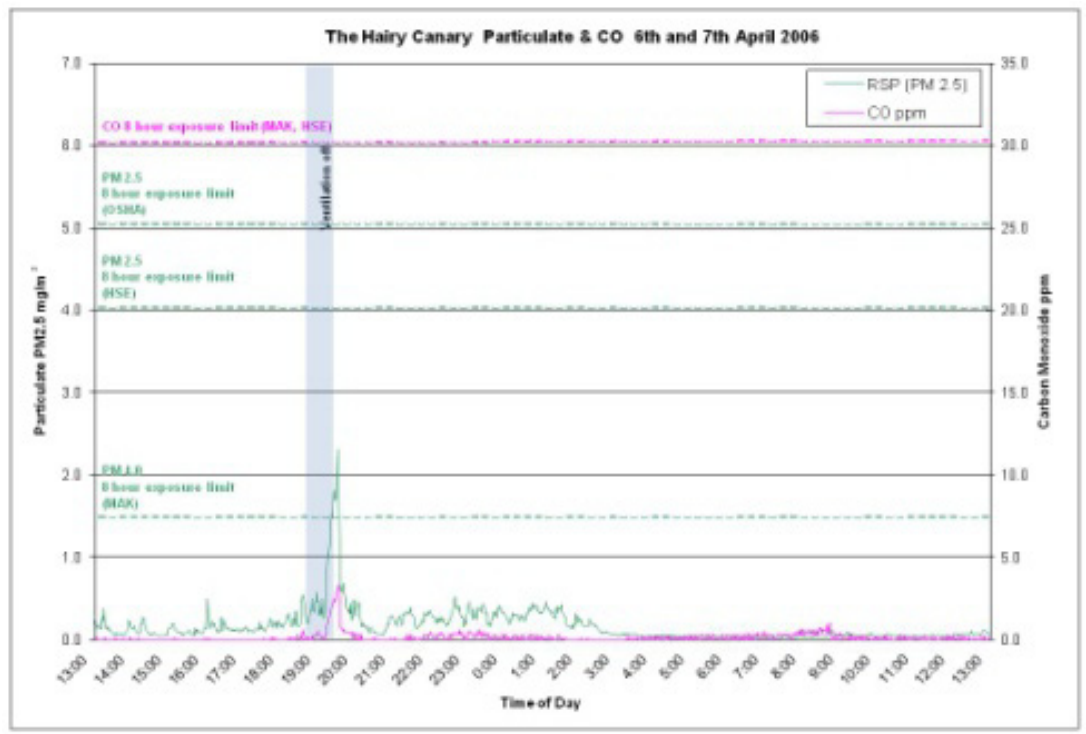

(b)

Figure 3: Hairy Canary monitoring. 


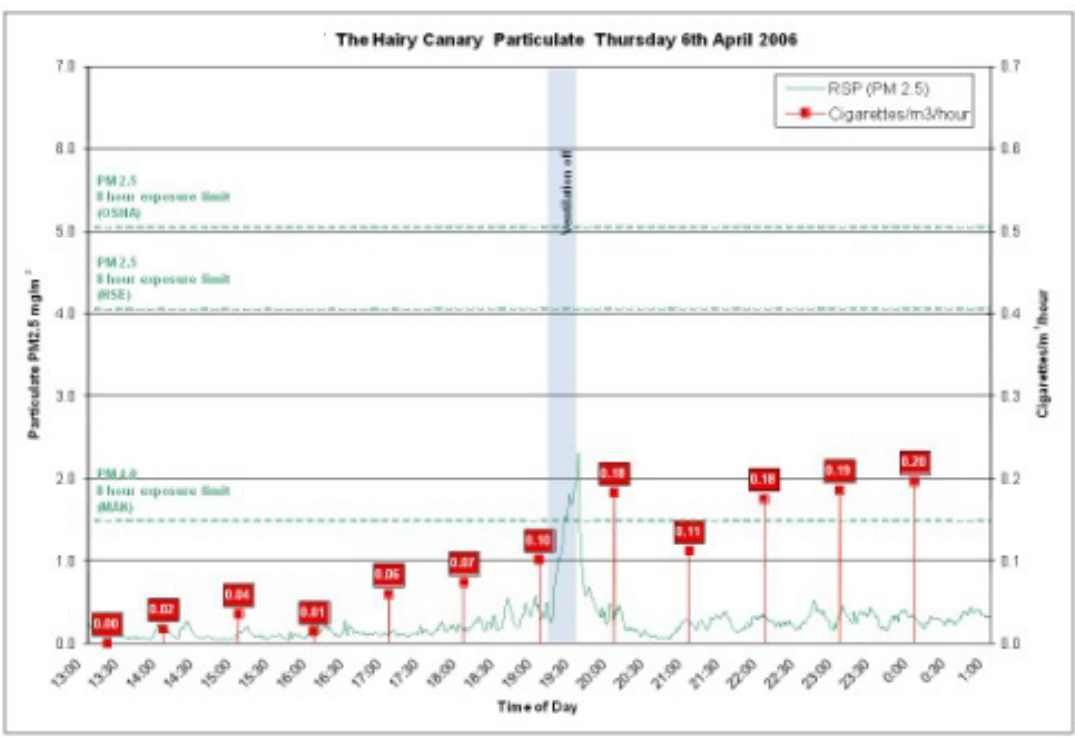

(a)

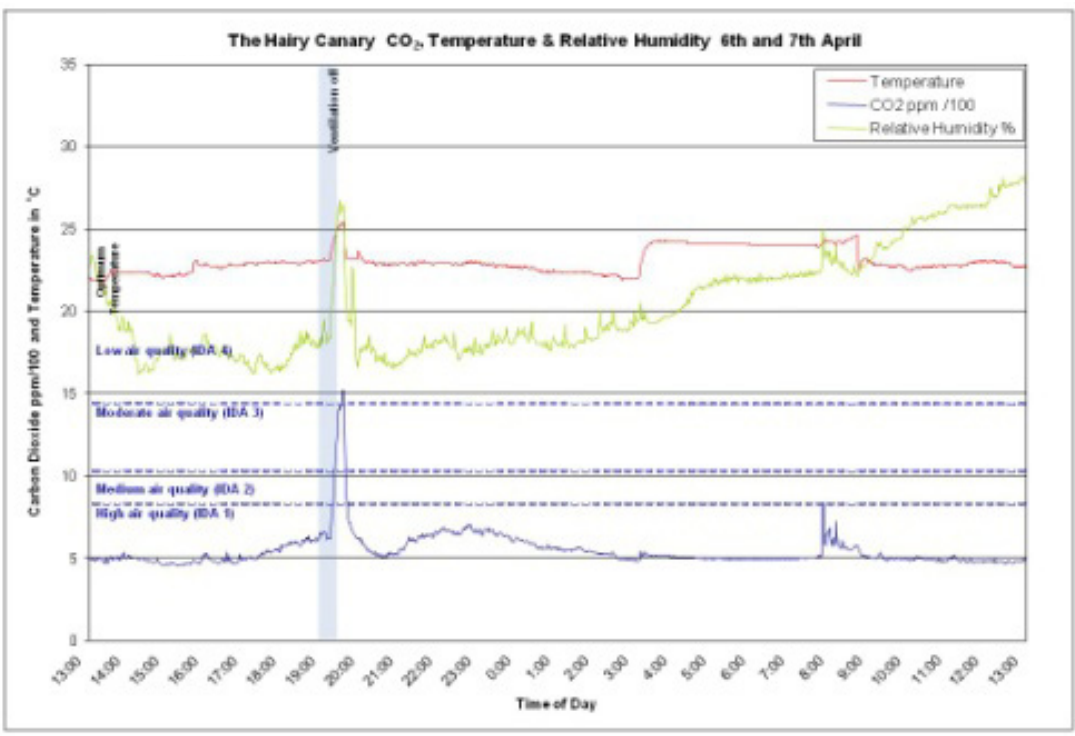

(b)

Figure 4: Hairy Canary monitoring. 


\subsection{Particulate (PM 2.5)}

The results of the monitoring for Respirable Suspended Particles (PM 2.5) can be seen in Figures 3(b) and 4(a). Figure 3(b) shows that with the ventilation equipment running particulate is limited to below $0.5 \mathrm{mg} / \mathrm{m}^{3}$. The figure shows that when the ventilation unit is out of service, the particulate level rapidly rises, on this occasion to almost $2.5 \mathrm{mg} / \mathrm{m}^{3}$. When the systems are re-instated, the readings return very quickly to their earlier levels.

\subsection{Cigarette count}

Peak consumption per hour was $56\left(0.20\right.$ cigarettes $/ \mathrm{m}^{3} /$ hour $)$. This is considered a heavy level of smoking for the space.

\section{Analysis of results}

These studies clearly demonstrate the ability of the ventilation system in this building to limit and control the concentrations of the parameters under consideration. The results presented are from instruments located close to the breathing zone of the bar staff.

\subsection{Bakers Arms, Waddesdon}

\subsubsection{8th October 2004}

The three air quality constituents recorded appear to fluctuate in tandem with both levels of smoking and ventilation and filtration intervention. The results from the 8th October when the equipment was running all evening show that contaminant levels are being controlled for the markers recorded. During this monitoring period, all parameters are well within recognised HSE occupational exposure levels.

\subsubsection{9th October 2004}

The results show that the equipment is still controlling the growth of contaminant levels for the markers recorded and that when the equipment is turned off the levels steadily increase until the equipment is re-instated. When the equipment is re-instated the levels fall very quickly to the earlier position. This appears as a very steep curve on the graph. This rapid decay represents a decrease of 80 to $90 \%$ in the case of the particulates, $80 \%$ in the case of carbon dioxide, and in the case of Carbon Monoxide, with the levels falling to zero (subject to the precision of the instrument), a decrease of almost $100 \%$.

\subsection{The Hairy Canary Irish pub, Brussels}

\subsubsection{6th April 2006}

The three air quality constituents recorded appear to fluctuate in tandem with the level of ventilation intervention. The results show that the ventilation equipment controls contaminant levels for the markers recorded and that when the 
equipment is turned off the levels rapidly increase until ventilation is re-instated. When the ventilation is re-instated the levels fall back very quickly to their earlier levels. This appears as a very steep curve on the chart. During this monitoring period, all parameters were well within recognised workplace exposure limits as noted.

\section{Conclusion}

These studies clearly demonstrate the ability of the ventilation system to limit and control the concentrations of the parameters under consideration to within recommended workplace exposure limits. The results are consistent with similar earlier studies, and are in fact at the better end of the range of results obtained from earlier studies, adding weight to the argument that appropriately designed ventilation systems significantly improve the air quality in buildings without increasing the energy requirements. The focus of the studies reported in this paper was to demonstrate how effective the fabric diffuser in displacement mode was in dealing with a particular contaminant, environmental tobacco smoke. Measurements of concentration to allow calculation of ventilation effectiveness were not taken; in fact there is no agreed protocol for determining the ventilation effectiveness for displacement ventilation. The very steep decay curves observed in the results suggest the effect of very high air change rates using more conventional dilution ventilation techniques, but they were achieved using modest air change rates with the displacement technique. The energy and hence carbon benefits of this should be self evident. The author has tested this benefit using the National Calculation Methodology for calculating the energy performance of non-domestic buildings in the UK, and these results will be the subject of a subsequent paper.

\section{References}

[1] BS EN 15251, Indoor environmental input parameters for design and assessment of energy performance of buildings addressing indoor air quality, thermal environment, lighting and acoustics, 2007.

[2] Office of the Deputy Prime Minister, Approved Document F - Ventilation, 2006.

[3] PD CR 1752, Ventilation for buildings. Design criteria for the indoor environment, 1999.

[4] Commission of the European Communities, Guidelines for Ventilation Requirements for Buildings. Report no.11, Directorate General for Science, Research and Development, Joint Research Centre - Environment Institute, EUR 14449 - European Concerted Action "Indoor Air Quality and its Impact on Man", Office for Publications of the European Communities, Luxembourg, 1992.

[5] Wyatt T., "The displacement ventilation with static cooling and heating approach to more natural indoor climates", Proceedings CLIMA 2000 Conference, Paper No. 69, 1993. 
[6] Geens A J, Graham M S and Alamdari F. Displacement Ventilation applications - an alternative view, Proceedings CIBSE Conference, Vol. 1 pp38 - 44, 1997.

[7] Abbas T, Displacement Ventilation and Static Cooling Devices, BSRIA COP 17/99 1999.

[8] Geens, A. J., A Critical Appraisal of the use of Displacement Ventilation in Commercial Buildings. PhD, University of Glamorgan, 2000.

[9] Butler D., Air conditioning using displacement ventilation to maximise free cooling, CIBSE Conference 2002.

[10] 1988 OSHA PEL Project Documentation, accessed 2nd March 2010.http://www.cdc.gov/niosh/pel88/npelname.html

[11] MAK exposure limits for diesel exhaust pollutants, accessed 2nd March 2010.http://www.dieselnet.com/standards/de/ohs.html

[12] Health \& Safety Executive, EH40/2005 Workplace exposure limits, 2005

[13] The European Standard EN 13779:2004 (E) Ventilation for non-residential buildings-performance requirements for ventilation and room-conditioning systems, $15^{\text {th }}$ October 2004.

[14] Dean J A. Lang's Handbook of Chemistry, 17th edition. 1979.

[15] Cains, T., Cannata, S., Poulos, R., Ferson, M. J. and Stewart, B. W., Designated "no smoking" areas provide partial to no protection from environmental tobacco smoke. Tobacco Control, 13, 2004, pp. 17 -22.

[16] BSRIA Technical Note 2/2002, Building-related Sickness Causes, effects, and ways to avoid it. Edited by Anu Palmer and Rosie Rawlings, 2002.

[17] CIBSE Guide A. Environmental Design Criteria, October 1999, pp 1-2 - 115. 